\title{
EL ENQUIRIDIÓN DE PERO DÍAZ DE TOLEDO
}

José LuIS HerRero Prado

Sabemos que Pero Díaz de Toledo escribió esta obra porque él mismo la cita en la Introducción a la Querella dela Gouernaçión ${ }^{1}$. Posiblemente, sin la declaración expresa que hace, hubiera pasado inadvertida, dado que diversas circunstancias la han mantenido en el olvido hasta ahora. A ello se suma la existencia de varias obras más que, con este mismo título, fueron escritas en diferentes épocas. Esta circunstancia fue lógico origen del camino emprendido por Ris Barbara Ann ${ }^{2}$, siguiendo a Round, N. G. ${ }^{3}$, para localizar el texto, quien estableció tres posibilidades, dejando el problema sin solución efectiva: a/ Traducción del Enchiridion de Epícteto, b/ Versión del Enchiridion de San Agustín a Laurencio. c/ Obra original de Pero Díaz de Toledo.

El término «enquiridión», del latino «enchiridion», procedente a su vez del griego «enkheiridion» («én» = en y «khéir» = mano) significa «lo que se

1 Ms. 1.250 de la Biblioteca del Palacio Real de Madrid. Obras de Gómez Manrique. Fol. 491. «Pensando de reposar del trabajo del libro Enchiridion, que por muchos años me touo ocupado, estando quasy enla conclusión e acabamjento de aquel, ocurrió que me fue dicho que en presencia dela muy...*

2 Riss Barbara, Ann: Pero Dlaz de Toledo's «Proverbios de Séneca». AN ANOTATED EDITION OF MS. S-II-10 OF THE ESCORIAL LIBRARY (Spanish text). University of California. Berkeley PH. D., 1979. XXVI.

3 Round, Nicholas G.: Pero Díaz de Toledo: a study of a 15 th century «converso* translator in his background. Diss. University of Oxford 1967, p. 510. 
tiene a mano» («libro manual», «libro portátil o pequeño», «manual o colección resumida de preceptos o enseñanzas»). Es un vocablo polivalente que se usó para designar cualquier tipo de obra que reuniera estas características y en ese sentido lo utilizó nuestro autor.

Del Enchiridion de Epícteto ${ }^{4}$ hemos localizado una única traducción, recogida en el códice 7.806 de la Biblioteca Nacional de Madrid. Ocupa los folios 1 r.-13 v. y le precede una reseña, donde se afirma que fue traducido por un estudiante teólogo, junto con una breve carta del intérprete al lector. Está dividido en sesenta y seis capítulos, donde aborda diversos temas relativos a la libertad y a las pasiones del hombre. La única relación que puede establecerse entre esta traducción y nuestro autor, aparte del título, es la de estar recogida en un códice con otras dos obras sospechosamente atribuibles a él: la traducción del Axioco (que no se parece en nada a la del códice 458 del Fondo Español de la Biblioteca Nacional de París, donde se recoge el suyo verdadero) y la Homilía de san Basilio, Attende tibi ipsi, que Mario Schiff cree probable de Pero Díaz. No parecen pruebas suficientes como para atribuirle su traducción, ni menos que sea ésta la que hizo bajo ese título.

Más remota aún parece la posibilidad del Enchiridion de san Agustín, teniendo en cuenta la predilección de Pero Díaz de Toledo y de los restantes traductores de la cámara del marqués de Santillana por los autores griegos y latinos, cuyas obras, procedentes de Italia, se esforzaron por introducir en la Península.

La tercera de las hipótesis que plantean los citados estudiosos es la única cuya verosimilitud se ha demostrado con el resultado de nuestras investigaciones: se trata efectivamente de una obra de creación propia, larga y laboriosa como corresponde al tiempo que declara haber trabajado en ella. D. José VillaAmil y Castro ${ }^{5}$ recoge en su catálogo, con el número 84 , una obra titulada Enchiridion de Petrus Didaci del (sic) Olmedilla, legum doctoris. No cabe duda que se está refiriendo a nuestro autor, como veremos.

${ }^{4}$ Esta obra, como se sabe, no fue escrita por Epícteto sino por Arriano, discípulo suyo, que redactó las notas tomadas durante sus clases y las publicó después de la muerte del maestro con el t́́tulo de Coloquios de Eptcteto. Más tarde resumió en una pequeña obra lo más importante de la doctrina, dándole el título de Enquiridión.

5 VILla-Amil y CASTRo, José: Catálogo de manuscritos existentes en la Biblioteca del Noviciado de la Universidad Central (procedentes de la antigua de Alcalá). Madrid, 1878, parte I. p. 26-27. 
Asegura además Villa-Amil y Castro, en una nota, que nuestro autor escribió este tratado en tiempo de don Juan II y Enrique IV y que fue pariente de Pedro de Toledo, lo que prueba definitivamente la tesis de la autoría.

Se confirma así, una vez más, la importancia que para la ciencia y la investigación desempeñan los trabajos y obras de catalogación. Numerosos manuscritos desaparecieron de la Biblioteca del Archivo Histórico de la Universidad Complutense en un incendio ocurrido durante la pasada Guerra Civil Española, sin que de ellos quede otra referencia que la descripción y el testimonio recogidos en el catálogo de Villa-Amil y Castro. Incluso a este códice, que se salvó de las llamas, hemos llegado por idéntica vía. Muchas bibliotecas con importantes fondos documentales carecen en la actualidad de un catálogo actualizado y organizado por diferentes conceptos, no ya publicado, sino, a veces, ni siquiera de uso interno, o en ocasiones con criterios muy peculiares. Por eso es encomiable la labor de quienes se dedican a este menester, árido y aparentemente estéril, pero primordial para el investigador.

1. MANUSCRITO DEL ENCHIRIDION

El manuscrito del Enchiridion, único que se conoce hasta el momento, se conserva, como decimos, en el Archivo Histórico de la Universidad Complutense de Madrid (antigua Biblioteca del Noviciado de la Universidad Central) con el número 84. Es un hermoso códice, restaurado con esmero y respeto a su imagen anterior. El volumen está encuadernado en piel marrón jaspeada, con seis nervios en el lomo y estampaciones doradas. En el segundo espacio entre los nervios tiene un tejuelo rojo con la leyenda: PETRUS DIDACI/ENCHIRIDION. En el tercero hay una «M» grande y en los restantes espacios aparecen grabados diversos motivos florales. Sus medidas son $425 \times 295 \times 70 \mathrm{~mm}$. y conserva la misma signatura que tenía cuando Villa-Amil y Castro hizo su catálogo, $n^{\circ} 84$. La foliación es doble, modernas y a lápiz ambas. Una situada en la parte inferior izquierda que empieza con «A» para el primer folio y otra en la parte inferior derecha que llega hasta 339 folios (no 341 que tenía en el catálogo de Villa-Amil). Está escrito a dos columnas y las cajas de escritura responden al siguiente modelo y medidas: 


\section{Cuadro n. ${ }^{\circ} 1$}

Caja de escrittura del ms. 84.

Archivo Historico de la Univesidad Complutense.

Enchiridion.

Pero Díaz de Toledo

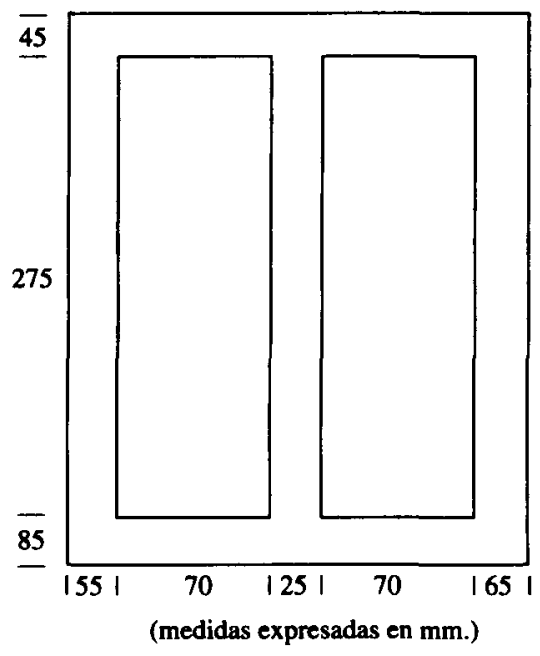

Es un códice monumental tanto por su tamaño como por el volumen, en el que figuran ordenados alfabéticamente numerosos conceptos relativos al Derecho. Presenta algunas diferencias con la descripción que del mismo hizo VillaAmil y Castro en su catálogo 6 . Le falta la introducción que cita Villa-Amil, lo cual se puede constatar también porque el número de folios actuales (339) no se corresponde con los que él asegura que tenía (341). Faltan pues lamentablemente dos folios, que debieron de ser los iniciales de la introducción.

6 VRla-AmIL y CASTRO, Jose: op. cit. p. 26. «Empieza absolutamente con las palabras: In hijs que juris sunt provocare, del prólogo tras del cual sigue el texto, donde están colocados, por orden alfabético, multitud de artículos sobre materias jurídicas, distinguiéndose por su extensión los de actio, actus, appelatio, citatio, clericus, filius, judex, lex, officium, procurator, rex, sententia y textis y por la materia sobre que versan los que tratan de la letra a de la sepultura de Adam, de adulatio, de amen, de auglia, de biblioteca, de cor, gustus, de musica, de perdix, etc. Al fin dice textualmente: Explicit enchiridion petri didaci del olmedilla, legum doctoris. Códice escrito a dos columnas, con iniciales adornadas de dibujos de colores, en 341 hojas de papel de 408 por 385 milímetros. Data del siglo XV». 
Además del éxplicit final, donde se declara sin ningún género de dudas quién es el autor del mismo, es evidente que se trata de una obra de Pero Díaz de Toledo: primero porque la materia que desarrolla se corresponde plenamente con los estudios de su especialidad: leyes civiles y canónicas; en segundo lugar por la extensión del mismo (341 folios según Villa-Amil) y por la organización (conceptos seleccionados y ordenados alfabéticamente), que justifican plenamente los años de trabajo que Pero Díaz de Toledo aseguró haberle dedicado $y$, finalmente, por el título «Olmedilla» que le añade al nombre, otorgado a nuestro autor en fecha indeterminada según consta en un documento de Alcalá de Henares, así como el grado de doctor en leyes.

Los títulos de cada definición aparecen escritos con letra minúscula pero de mayor tamaño. El paso de una letra a otra (A, B, C, ...) lo acompaña con capital adornada. Intercala calderones rojos y negros para marcar el comienzo de nueva letra. En la parte superior del margen derecho de las páginas impares figura la relación de los conceptos que desarrolla en esa página y en la anterior, lo que facilita enormemente el manejo y localización de cada término. Está escrito en papel sin filigrana. Es un tratado extensísimo, laborioso y escrito en latín. Tiene también algunas glosas marginales de letra diferente y de difícil interpretación. Hay una guarda blanca al principio y otra al final. Comienza en el fol. 1 r. «in. r. nimjna devollusione detegenda...», «Aborto: mulier abortum facies punjtur m. 1. diu[in]us p. de extra ordina...» A partir del folio 75 es diferente la letra, por lo que concluimos que debieron de intervenir dos o más copistas. Se advierten numerosas incorrecciones y vulgarismos latinos («devollusione», «del Olmedilla», etc.), así como vacilaciones t/c («citatio»/«apellacio») tan imputables al autor como a los copistas del códice.

La relación de conceptos que aparece en el margen derecho de las páginas impares está escrita con criterios muy distintos de los adoptados para la definición del concepto, utilizando «u» por «v», «j» por «j», etc. y desarrollando las abreviaturas que aparecen en el texto. Ello es una prueba más de la intervención de varios copistas en la elaboración del manuscrito, lo cual es sospechable casi solamente por su volumen y extensión. En el anexo final recogemos la totalidad de los epígrafes que integran el manuscrito.

\section{CONTENIDO DE LA OBRA}

Ninguna otra obra de este autor, de las conocidas hasta ahora, aborda temas de contenido jurídico. No parece lógico que un hombre de leyes dedicase todos sus esfuerzos a la traducción y composición de obras puramente literarias 
sin escribir una sola relativa a su especialidad. Sin embargo, el manuscrito en cuestión compensa con creces su inclinación hacia la literatura, puesto que, como decimos, se trata de una obra amplísima, minuciosa y densa.

El texto se presenta en dos columnas y recoge, por orden alfabético, numerosos conceptos jurídicos y de carácter general, entre los que se advierte predilección por los más especializados, así destacan por su extensión acceptilacio, actus, allienare (fol. 14 v.-16 r), appellacio (fol. 22 v.-27 r.), citatio (fol. 49 v.-54 v.), dispensacio (fol. 94 v.-96 v.) excepcio (fol. 118 v.-121), filius (fol. 143 v.-145 v.), judex (fol. 188 r.-193 r.), juramentum (fol. 193 v.-197 r.), lex (fol. 203 v.-206 v.), notarius (fol. 232 v. -235 r.), etc.

Por su letra, la circunstancia de haber sido escrito en latín, e incluir además numerosas abreviaturas relativas al Derecho es de difícil interpretación. Como su nombre indica, fue concebido para consulta y apoyo a la labor judicial que durante largo tiempo desempeño nuestro autor. Por ello no es exagerada la alusión que hace a los muchos años que le tuvo ocupado su elaboración 7 . Al igual que en nuestros días cualquier especialista necesita obras de consulta, seguramente Pero Díaz de Toledo depositó en este texto todos los conocimientos adquiridos en la universidad y los que durante el ejercicio de la profesión fue acumulando, para poder así acudir a él y resolver con facilidad las dudas que le surgieran en su trabajo. La obra pudo muy bien ser el trabajo de recopilación de la experiencia laboral de toda su vida en el campo del Derecho. Tampoco parece probable que hiciera mucho uso de ella, dado que su muerte acaecí al año siguiente.

Teniendo en cuenta que lo cita en la Introducción a la Querella, y que ésta fue compuesta en torno a 1465, es evidente que el Enchiridion fue terminado algún año antes, pero no muchos, porque Díaz de Toledo presenta el tránsito de aquél a ésta como una carga que le apremia terminar cuanto antes.

Aunque la localización de este códice viene a completar el catálogo de las obras del autor, y a rellenar el hueco de la pieza perdida, su importancia es preferente para el Derecho - objeto de consideración en el mismo- por encima de las demás disciplinas, pero no la única. Se suscita así una vieja y habitual cuestión al permitir enjuiciar a un mismo personaje desde perspectivas o campos diferentes que, en muchos casos, lejos de contraponerse, se complementan y dibujan un perfil más humano y auténtico del autor. El Enchiridion, como obra jurídica, contribuye a determinar los conocimientos y experiencia de Díaz de Toledo en el campo del Derecho (no debe olvidarse que fue uno de los doce jueces que intervinieron en el proceso que se siguió contra don Alvaro de Lu-

7 Vid. nota 1. 
na, para cuyo difícil y delicado napel se seleccionarían los juristas más relevantes y exquisitos). Descubre a la vez las preferencias, debilidades o preocupaciones del compilador y colabora, al mismo tiempo, a completar la historia del Derecho de su tiempo. De su análisis es posible obtener conclusiones válidas sobre sus creencias e ideas, puesto que pueden advertirse las influencias que se reflejan en ella. Este es el caso de conceptos religiosos que, posiblemente por afinidad con el Derecho Canónico, o por ser él doctor en ambas disciplinas, se hallan insertos en el texto sin corresponderles en rigor el lugar que ocupan.

Poco o nada podemos asegurar sobre el procedimiento seguido en la elaboración del manual. Sin embargo, son muchas las conjeturas susceptibles de aplicación al caso, puesto que es difícil suponer que, tratándose de una obra de tal envergadura, emprendiera él solo el trabajo de recogida de datos y ulterior redacción. Es evidente que, para las cuestiones más delicadas, controvertidas o complejas, contaba con la inestimable ayuda de su tío, el Relator de Juan II, Fernando Díaz de Toledo, así como de otros juristas que, al igual que él, frecuentaban los círculos de la corte. 